\title{
Dynamic Response Study of a Single Tower Cable Stayed Bridge using Finite Element Method
}

\author{
Muhammad Habib a , Naik Muhammad ${ }^{\text {a }}$, Saeedullah Jan Mandokhail a , Zafar Baloch ${ }^{\text {a }}$, Muhammad Irfan ${ }^{\text {b }}$, \\ Azmatullah Khan ${ }^{\text {a }}$, Muhammad Akram ${ }^{c}$, Gohram Khan ${ }^{a}$, Anila Ali ${ }^{\text {a }}$, Ali Asgher ${ }^{\text {a }}$, Samiullah Khan ${ }^{\text {d }}$ \\ a: Faculty of Engineering \& Architecture, BUITEMS \\ b: Faculty of Management Sciences, BUITEMS \\ c: Faculty of Information \& Communication Technology, BUITEMS \\ d: Faculty of Life Sciences \& Informatics, BUITEMS
}

* Corresponding authorEmail: habibcivilian05@gmial.com

\begin{abstract}
Cable stayed bridges are most widely used in the modern medium to long bridge construction due to their efficient response, economic viability, faster construction, and eye-catching aesthetics. The dynamic response of a single tower cable stayed bridge is studied by performing both nonlinear static and dynamic analyses using finite element method based software ANSYS. A three dimensional bridge model was developed using ANSYS. The steel cables were simulated using a single element approach to minimize the time and data use. Due to the complexity of cable stayed bridges, it is tried to avoid the convergence problems by adopting the displacement convergence approach. The bridge exhibits complex modal shapes due to the coupling effects for the free vibrations. The response of the bridge in vertical direction is more elastic and flexible as compared to the longitudinal and transverse direction. Response of the critical sections of girder, tower, and cables was also studied by time-history analysis using the ground acceleration data of the EICentro 1940 earthquake. A 10 second ground data with 0.0001 second time step was used. It was observed that stiffness in the vertical direction is a key player in the dynamic behavior of the cable stayed bridge. The response of the right and left span is similar which adds to the accuracy of the analysis. Time history analysis of the bridge shows that the largest displacements or peak responses are not related to the peak ground accelerations, rather they are dependent on many other factors like bridge stiffness, nature of the earthquake ground excitations and mass distribution. However, the results show the general trend of cable stayed bridges.
\end{abstract}

Keywords- Dynamic Behavior, Single-tower Cable Stayed Bridge, Time History Analysis, ANSYS

Date Received 03-09-2019

Date Accepted 11-10-2019

Date Published 18-12-2020

\section{INTRODUCTION}

$\mathrm{C}$ Cable stayed bridges (CSB) are the most widely used for medium to long span bridges due to their aesthetics, rapid construction, and economic viability. Cable stayed bridges have span lengths of $200 \mathrm{~m}$ to $1200 \mathrm{~m}$. $90 \%$ of the modern long span bridges are cable stayed bridges [1]. To construct long span bridges having slender sections are possible only if highly advanced and precise techniques are used to predict the structural response due to dynamic loadings. Dynamic response studies are the main focus of the researchers since the collapse of Tocoma Narrows Bridge in 1940 [2, 3]. A cable stayed bridge can be designed by performing linear dynamic analysis using two dimensional model [4]. Equation of motions was given considering the non-linear behavior of theoretical 3-D models [5]. The dynamic response of the concrete cable stayed bridge was studied considering the effect of cables [6].

Moreover, the response of the bridges under earthquake loads got attention in the mid 1930's. Cable stayed bridges usually have a better response to the earthquake and other dynamic loads induced because of their flexible structure, relatively long basic vibration periods and low spectral accelerations. Very few supports are present in cable stayed bridges which allow a large relative movement which adds to its dynamic behavior. Parvez, S. and M. Wieland studied the Jamuna Bridge based on the spectrum analysis and concluded that it can resist a ground acceleration of $0.216 \mathrm{~g}$ [7]. But on the other hand, large amplitudes due to earthquake or dynamic loads are produced because of its high flexibility, light weight, and low damping properties. To reduce these amplitudes different external damping systems are used but the economy is still needed to be investigated [8]. With increasing lengths of the main span, the effects of wind and other dynamic forces increases [9].Seismic response studies of the cable stayed bridges are the focus of the researchers since the 1980's [10-13].

In this paper, the dynamic response of a single tower cable stayed bridge is studied. Natural frequencies, mode shapes, and their contribution is analyzed with the major emphasis is on the dynamic response of girder and tower of cable stayed bridges.

\section{ModelLING OF THE BRIDGE USING THE FINITE ELEMENT METHOD}

Due to the complex behavior of the CSBs, accurate structural analyses were a challenging task. Elastic and deformation theories were used for the static analysis of the cable stayed 
bridges. Elastic theories are safe but not economical because they are based on the linear material behavior. For shorter span and rigid stiffened structures, these methods can be used but for long span cable stayed bridges they are not very useful. Deflection theories consider the deformed shape and give more economical and slim cross sections. With the advancement in computer technologies, it is now possible to do static and dynamic analysis with greater accuracy.

The finite element method is very efficient for the idealization of the structure based on digital analysis. The discrete finite element model is one of the most effective nonlinear analysis tools, based on finite deformation theory, and is used for cable stayed bridges. Finite deformation theory considers all types of nonlinear sources.

The finite element method can be used to study the effect of complex structural responses such as tower displacements, cable elongations and support conditions. 2-D and 3-D sub and super-structure of the cable stayed bridges can be modeled using beam and truss elements [14-16]. A finite element based 3-D model of cable stayed bridge is developed using ANSYS 12.1. CSB is a complex bridge system, therefore, different types of elements are used to model the deck, tower, and cable system of the bridge [17]. In this model, the box girder is modelled using a three node Beam 189 element which is based on the Timoshenko beam theory. It can give shear forces, deformations, and wrapping. Cables are modeled using link 10 element [18].

A pre-stressed concrete box girder bridge having a span of (20 $+32+32+20) \mathrm{m}$ is considered for analysis. A single tower, made up of reinforced concrete, with a harp cable configuration is adopted. Constant cross section for the tower is used to avoid the modelling difficulties. Bridge is 10.5 meters wide. The ANSYS model of the bridge is given in Fig. 1. In bridge modeling, boundary conditions are given as: the tower base is modeled as a fixed end and the structure interaction with soil is neglected. Its rotations and translations in all directions are constrained. This confirms the classical cable stayed bridges design philosophy. Translations in transverse and vertical directions and torsional rotations are all restricted allowing only the rotations for the deck and abutment connections. The complete dynamic response of the cable stayed bridges is based on the tower and deck connection. For deck and tower, only longitudinal displacement is allowed restricting all other translations and rotations. This is a floating design of the bridges which is suitable and implemented in the earthquake prone zones.

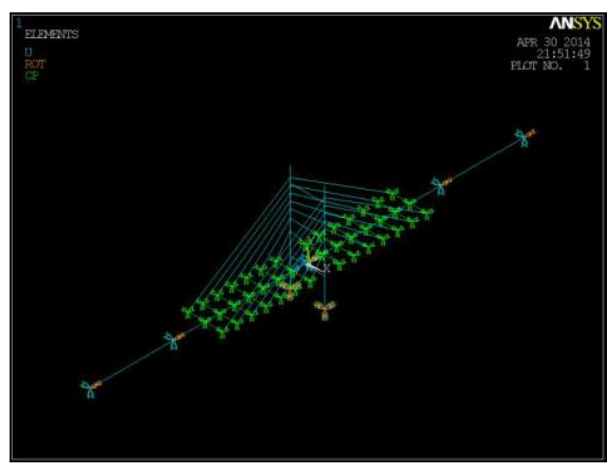

Fig. 1. Symmetric view of the 3DBridge Model

\section{PROPERTIES OF THE MATERIALS USED}

Concrete and steel are used to model the girder, tower, and cables. The linear elastic material model is used for concrete. Tower is the major contributor in the CSB. Therefore, high strength concrete (M50) is used for tower construction. The concrete used for the deck slab is an M40 and M30 strength is used for other components of the bridge. The elastic modulus for the concrete was taken as $35 \times 10^{3} \mathrm{MPa}$. Normal weight concrete having a unit weight of $2400 \mathrm{~kg} / \mathrm{m}^{3}$ is used in the bridge construction. Galvanized wires are used to model the cables. The modulus of elasticity of steel used is $195 \times 10^{3} \mathrm{MPa}$. The unit weight of the steel is the same as normal deformed steel $\left(7850 \mathrm{~kg} / \mathrm{m}^{3}\right)$. Poisson's ratio for concrete was considered as 0.2 and 0.3 for the steel wires.

\section{RESUltS AND DISCUSSIONS}

For the dynamic response of the CSBs, static, modal, frequency and time-history analysis is important.

\section{A. Static analysis/gravity analysis under dead loads}

Dead loads are the major portion of the structure weight and are the same for the cable bridges. The overall structural stiffness is affected by the dead loads too. Deformed shapes of the bridge are important before the dynamic analysis. The deformed shape is obtained by the static analysis under the bridge self-weight. The dead loads are calculated directly by the ANSYS using geometric dimensions and material properties. Under the static loads, the bridge deck gives maximum deflection of $2.6 \mathrm{~mm}$ as shown in Fig. 2.

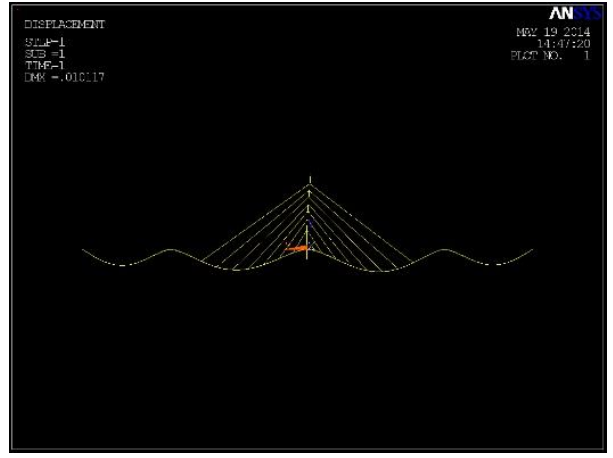

Fig. 2. Deformed or Deflected shape of Cable stayed bridge under its own weight

The tower and the girder of the bridge are modeled using beam element, thus the bending moments and axial forces are dominant. In static analysis, axial stiffness and flexural stiffness are considered to be uncoupled. With the increase in the deflections and deformations, axial and bending forces interact with each other. The member is deformed in the lateral direction too which alters the flexural stiffness of the member due to the extra bending. Therefore, interaction should be considered as it affects the overall stiffness of the bridge structure.

Cables show small geometric nonlinearities under static loads mostly due to the sagging effect along with geometric changes and other forces. Deformations increases with the consideration of gravitational forces, therefore, analysis of bridges under gravity loads must be performed. In Fig. 3 the deformations touch $10.12 \mathrm{~mm}$. 


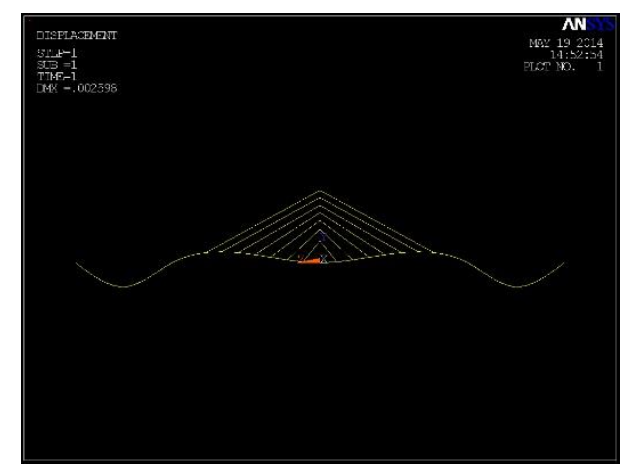

Fig. 3. Deformed shape of the bridge model under gravity loads

\section{B. Modal Analysis of the Cable Stayed Bridge}

Due to the high flexible nature of the CSBs, a study of the dynamic response analysis under different loads is important. The most effective analysis to study the modal shapes and natural frequencies of the structures is to perform the modal analysis. Longitudinal, transverse, vertical, coupled and torsional mode shapes can be obtained by performing the Modal analysis of the 3-D model. ANSYS uses the Block Lanczos method which is based on the principle of the eigenvectors extraction technique. In the modal analysis, orthogonal forces and the effect of the coupling is considered. The frequency of the initial 10 modal shapes is given in Table 1 .

Table 1: Modal shapes and frequencies

\begin{tabular}{|l|l|l|}
\hline $\begin{array}{l}\text { Mode } \\
\#\end{array}$ & $\begin{array}{l}\text { Mode } \\
\text { Frequency } \\
(\mathrm{Hz})\end{array}$ & Details of the mode Shape \\
\hline 1 & 2.58 & Coupled shape \\
\hline 2 & 4.29 & Transverse mode \\
\hline 3 & 4.81 & Vertical mode \\
\hline 4 & 6.24 & Vertical mode \\
\hline 5 & 6.76 & Vertical mode \\
\hline 6 & 7.40 & Longitudinal mode \\
\hline 7 & 8.45 & Vertical \\
\hline 8 & 8.72 & Vertical \\
\hline 9 & 9.11 & Complex \\
\hline 10 & 10.24 & Longitudinal Drag \\
\hline
\end{tabular}

The first 10 mode shapes can be seen in Fig. 4 to

Fig. 13.

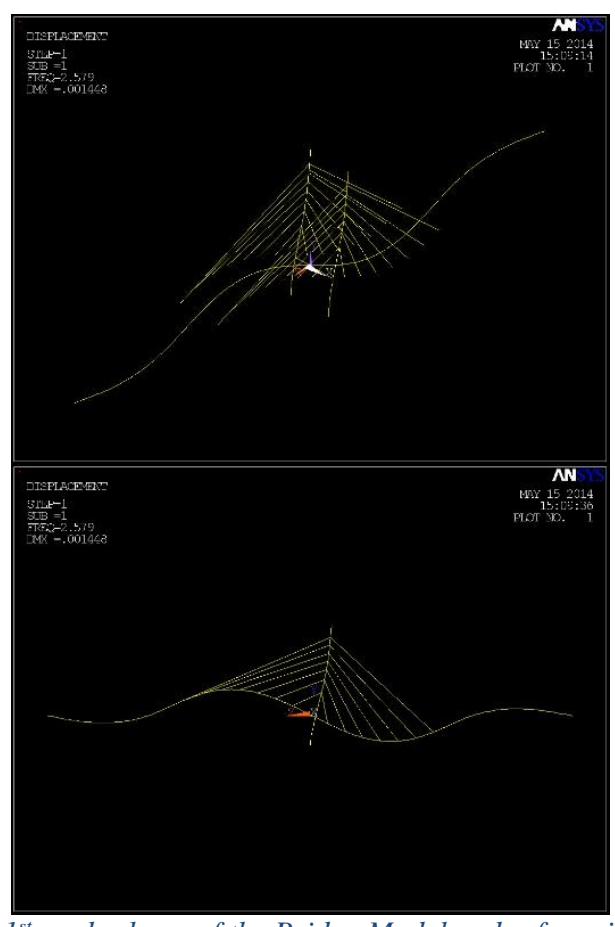

Fig. 4. $1^{\text {st }}$ mode shape of the Bridge Model under free vibrations

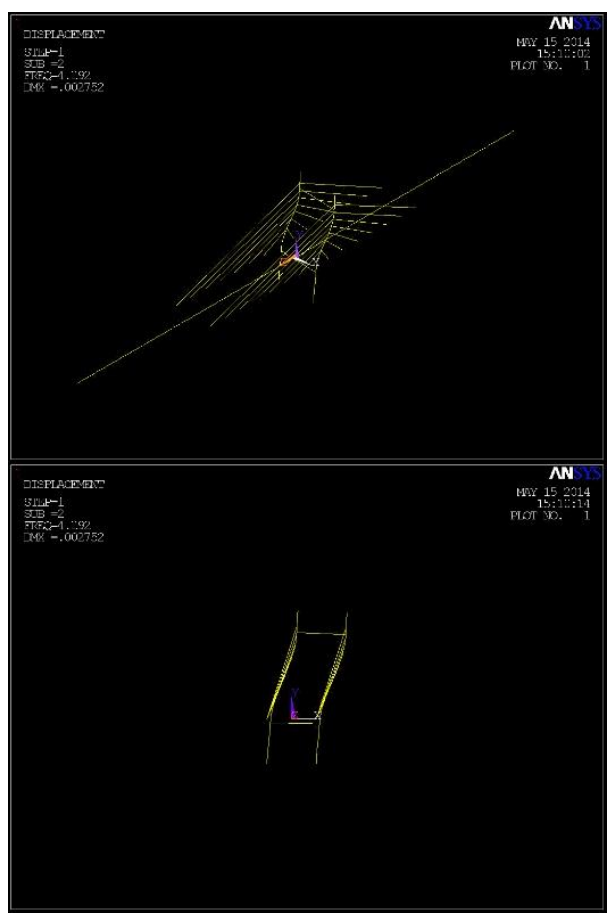

Fig. 5. $2^{\text {nd }}$ Mode shape of the Bridge Model under free vibrations

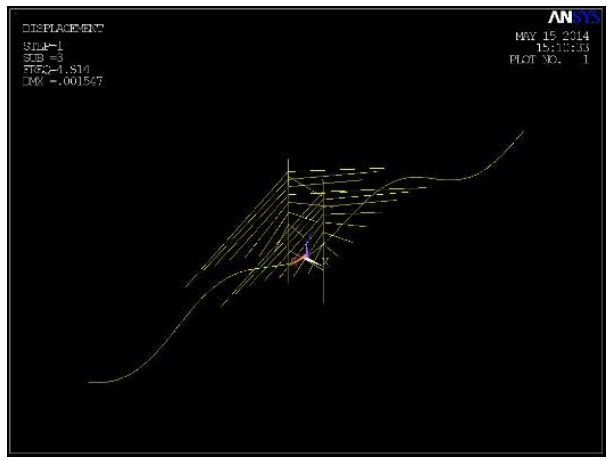


Journal of Applied and Emerging Sciences Vol (10), Issue (02)

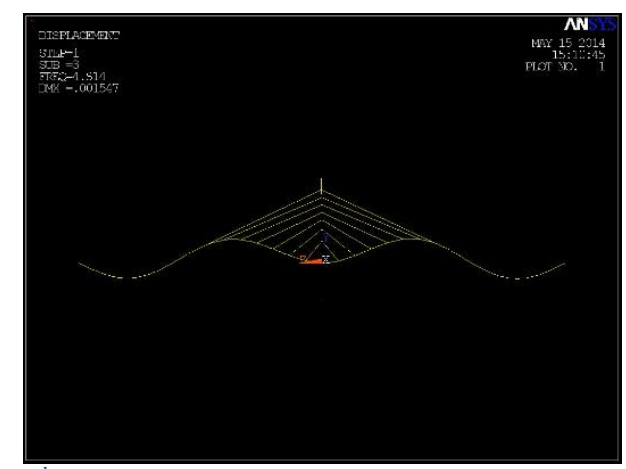

Fig. 6. $3^{\text {rd }}$ mode shape of the Bridge Model under free vibrations

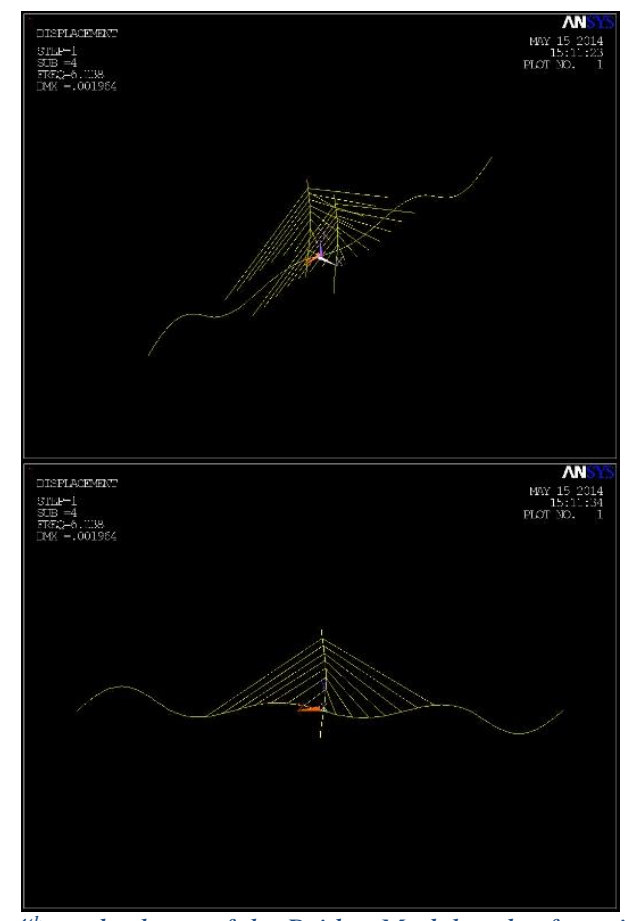

Fig. 7. $4^{\text {th }}$ mode shape of the Bridge Model under free vibrations

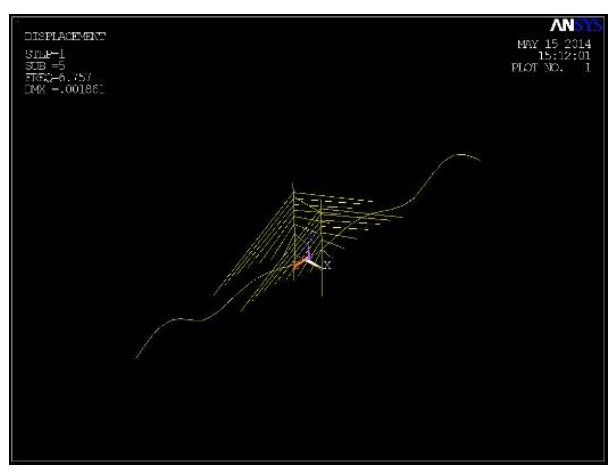

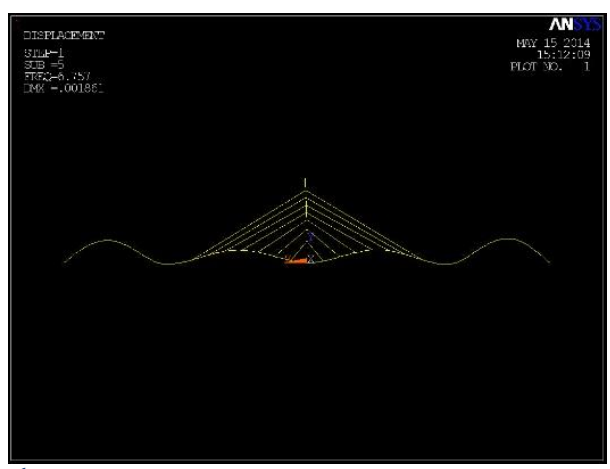

Fig. 8. $5^{\text {th }}$ mode shape of the Bridge Model under free vibrations

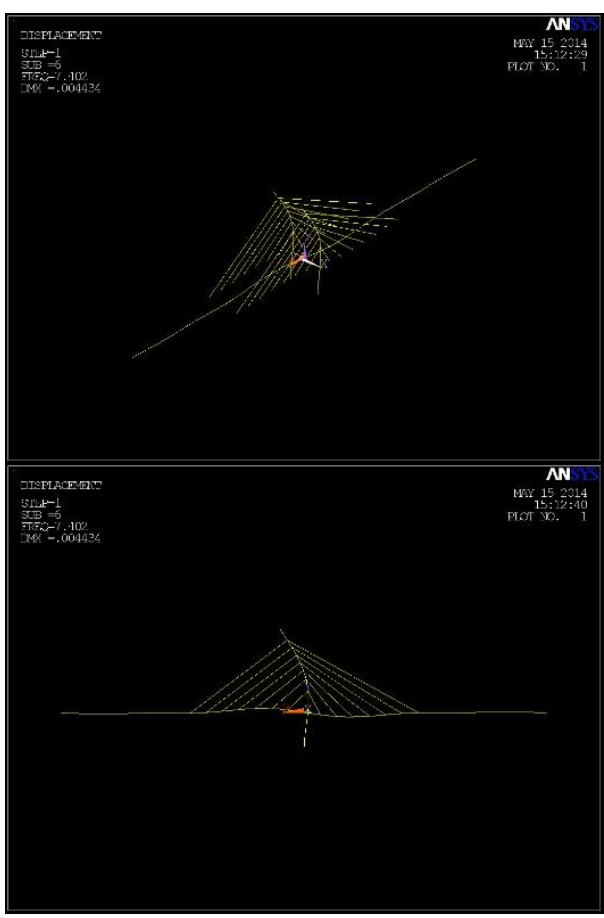

Fig. 9. $6^{\text {th }}$ mode shape of the Bridge Model under free vibrations

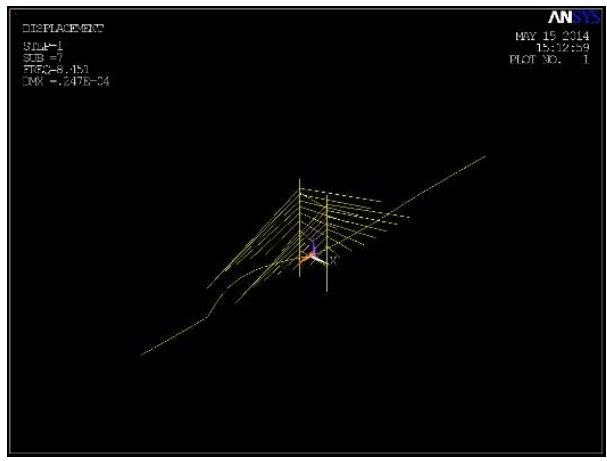




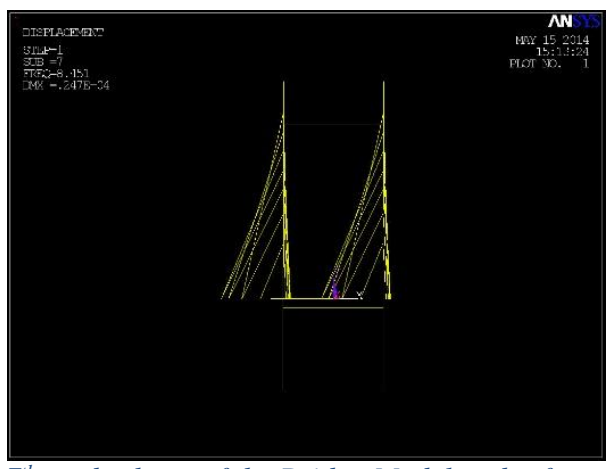

Fig. 10. $7^{\text {th }}$ mode shape of the Bridge Model under free vibrations

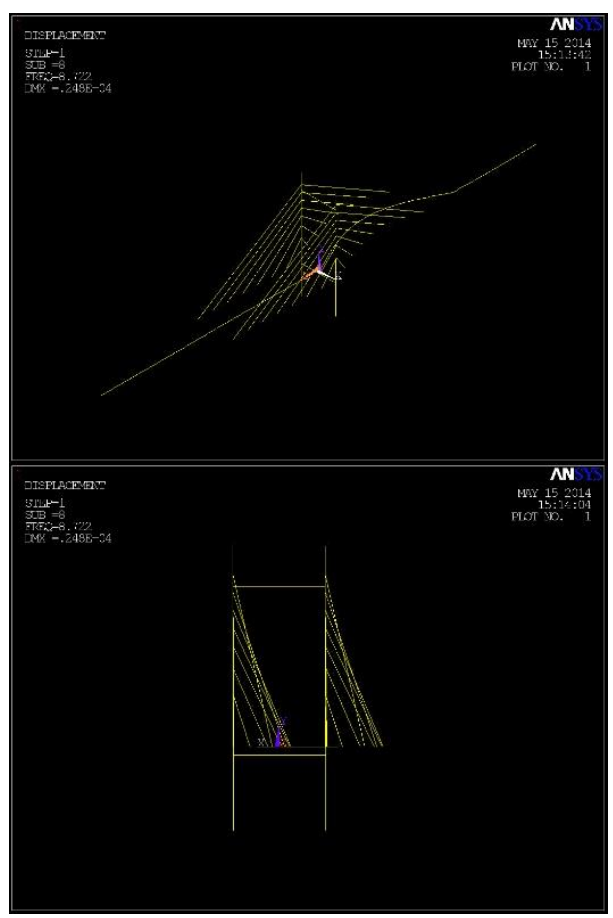

Fig. 11. $8^{\text {th }}$ mode shape of the Bridge Model under free vibrations

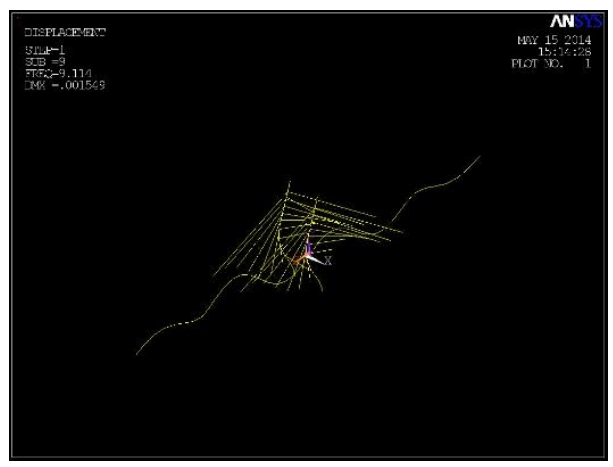

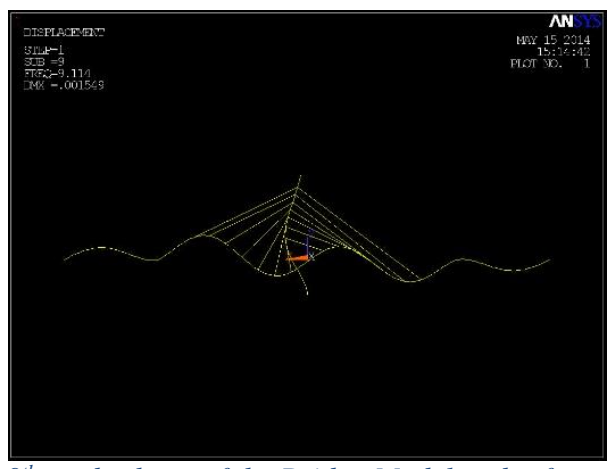

Fig. 12. $9^{\text {th }}$ mode shape of the Bridge Model under free vibrations

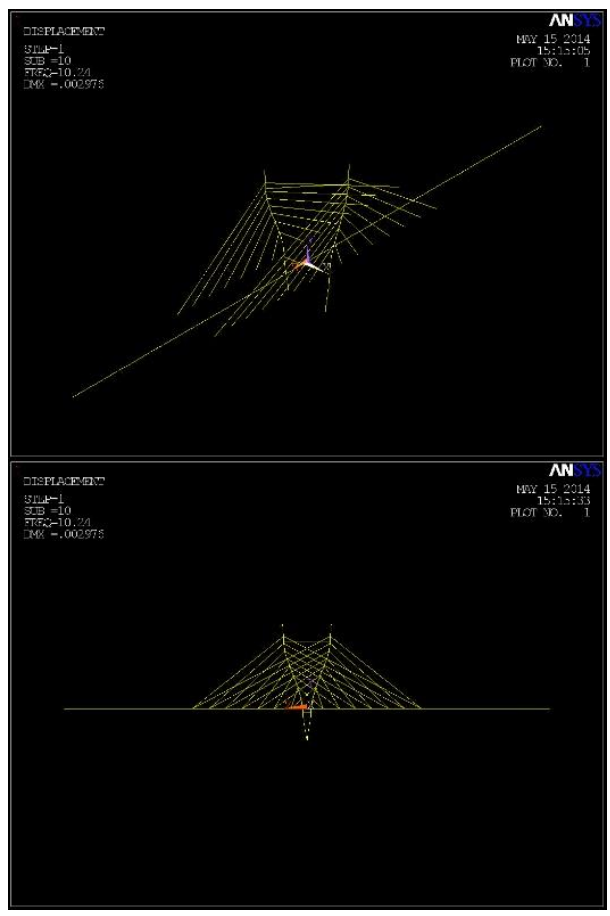

Fig. 13. 10 $0^{\text {th }}$ mode shape of the Bridge Model under free vibrations

\section{TIME HISTORY ANALYSIS AND RESPONSE}

The 3-D model of cable stayed bridge is analyzed using a moderate earthquake ground motion to study its dynamic behavior under the EI-Centro (1940) earthquake data. The peak ground acceleration (PGA) and the corresponding frequency is $0.348 \mathrm{~m} / \mathrm{s}^{2}$ and $1.75 \mathrm{~Hz}$ respectively. The ground motion data in three directions (longitudinal, transverse and vertical) is shown in Fig. 14 to Fig. 16.

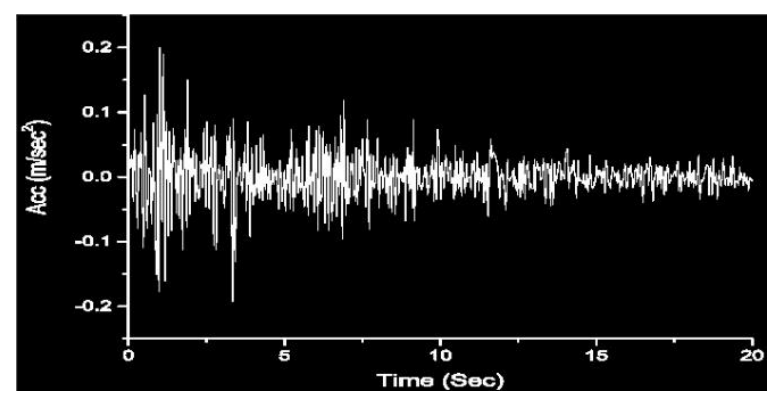

Fig. 14. Longitudinal Ground Accelerations of EI Centro Earthquake 


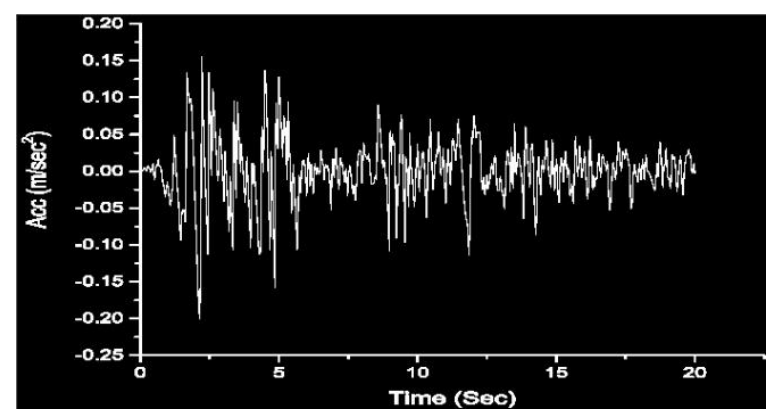

Fig. 15.Transverse Ground Accelerations of EI Centro Earthquake

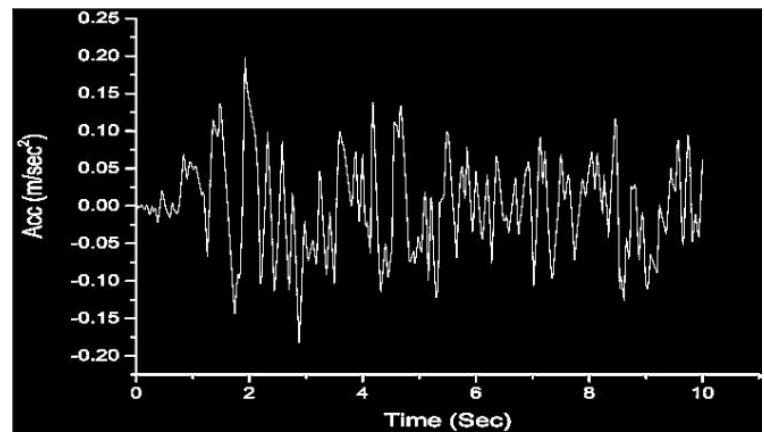

Fig. 16.Vertical Ground Accelerations of EI Centro Earthquake

\section{1) Behavior of the box girder}

Three dimensional time history analysis is performed with a time step of 0.0001 second. The response of the box girder at critical sections (mid-span, center of the right span) is shown in Fig. 17 to Fig. 22

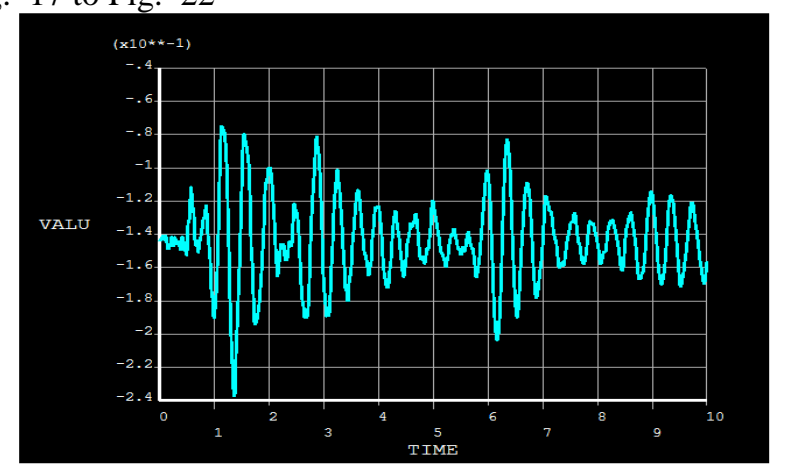

Fig. 17. Peak Vertical Displacement of box girder under three dimensional earthquake accelerations

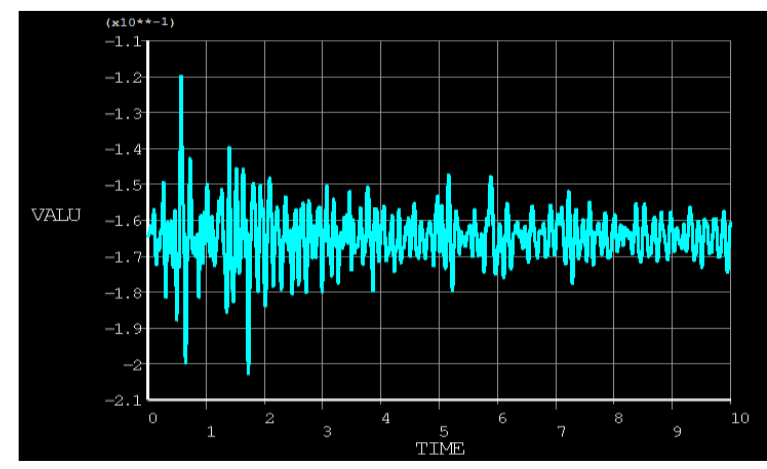

Fig. 18. Peak Transverse Displacement of box girder under three dimensional earthquake accelerations

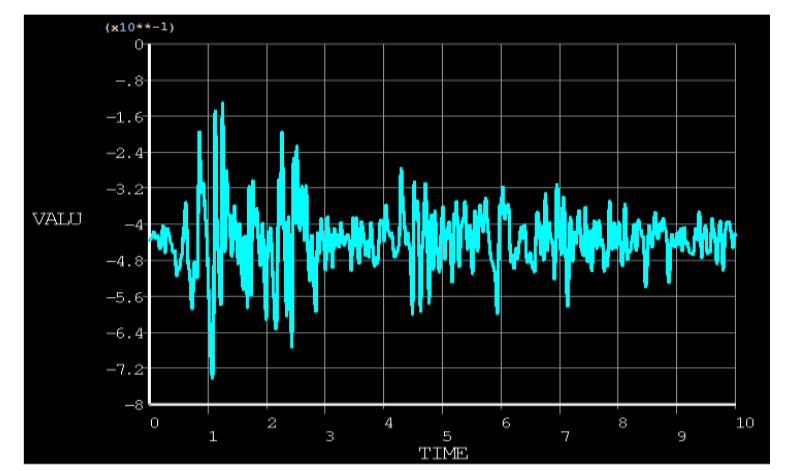

Fig. 19. Peak Longitudinal Displacement of the box girder under three dimensional earthquake accelerations

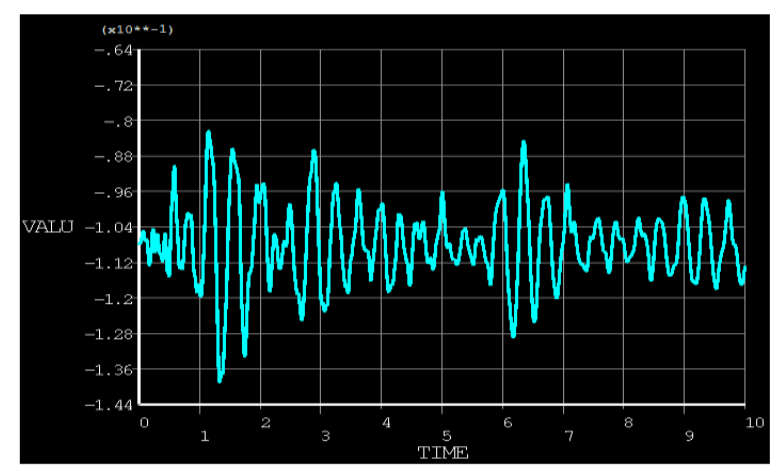

Fig. 20. Vertical Displacements of Right Span midpoint under three dimensional earthquake accelerations

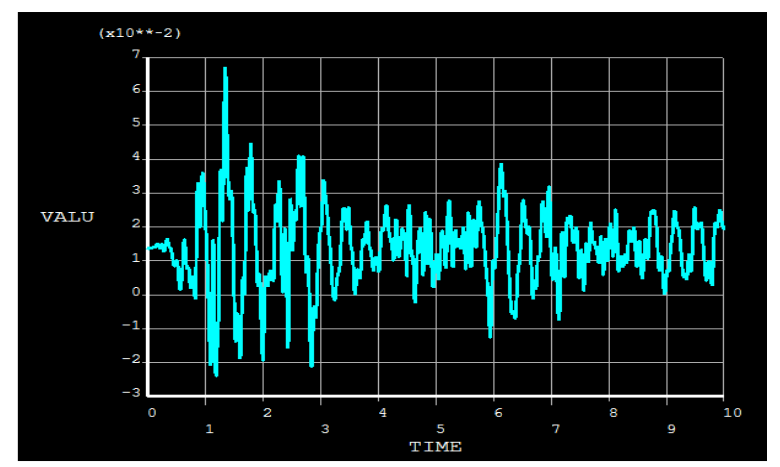

Fig. 21. Transverse Displacements of Right span midpoint under three dimensional earthquake accelerations

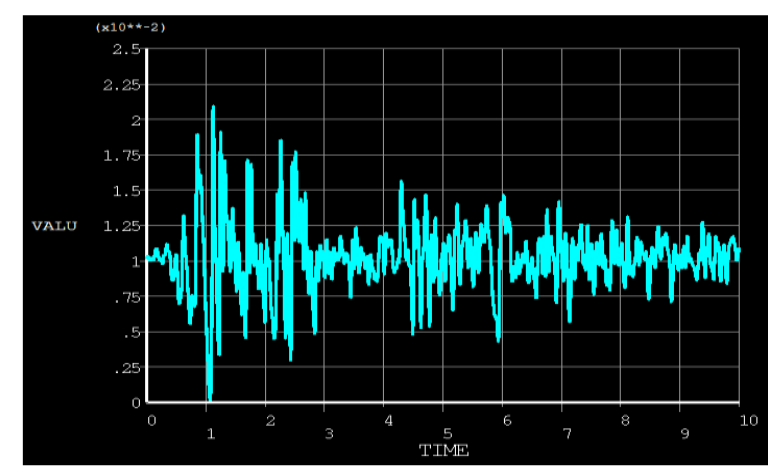

Fig. 22. Longitudinal Displacements of Right span midpoint under three dimensional earthquake accelerations

Peak girder responses are given in tabulated form in Table 2. Vertical direction is more flexible and susceptible to deformations as compared to other directions. Therefore, stiffness in the vertical direction is a key player in the dynamic 
behavior of the CS bridge. The response of the right and left span is similar which adds to the accuracy of the analysis.

Table 2. Box Girder Peak Displacements

\begin{tabular}{|l|l|l|l|}
\hline $\begin{array}{l}\text { Girder } \\
\text { location }\end{array}$ & $\begin{array}{l}\text { Vertical } \\
\text { Deformations } \\
(\mathrm{cm})\end{array}$ & $\begin{array}{l}\text { Transverse } \\
\text { Deformations } \\
(\mathrm{cm})\end{array}$ & $\begin{array}{l}\text { Longitudinal } \\
\text { Deformations } \\
(\mathrm{cm})\end{array}$ \\
\hline At Tower & 28 & 21 & 7.6 \\
\hline $\begin{array}{l}\text { Mid Span } \\
\text { (Right) }\end{array}$ & 13.6 & 7 & 2.1 \\
\hline $\begin{array}{l}\text { Mid Span } \\
\text { (Left) }\end{array}$ & 13 & 6.8 & 2.0 \\
\hline
\end{tabular}

2) Behavior of the Tower under the earthquake excitations The dynamic behavior of the tower of the CSB is observed and its behavior at critical sections is given in Fig. 23 to Fig. 25.

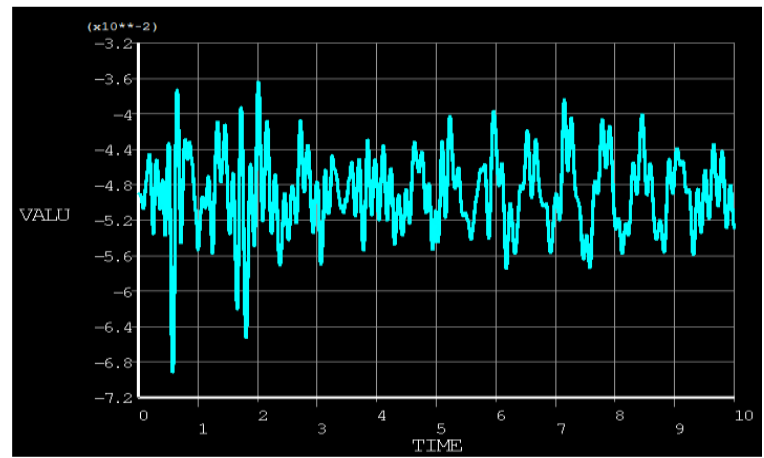

Fig. 23. Vertical Displacements of the top of tower under earthquake excitations

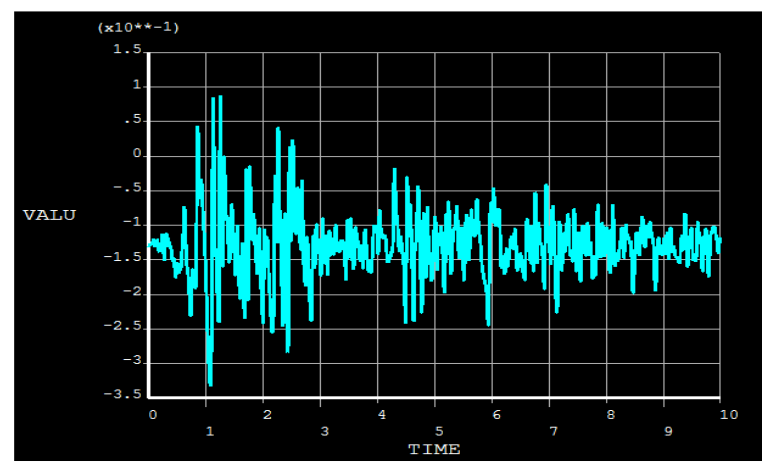

Fig. 24. Transverse Displacements of top of tower under earthquake excitations

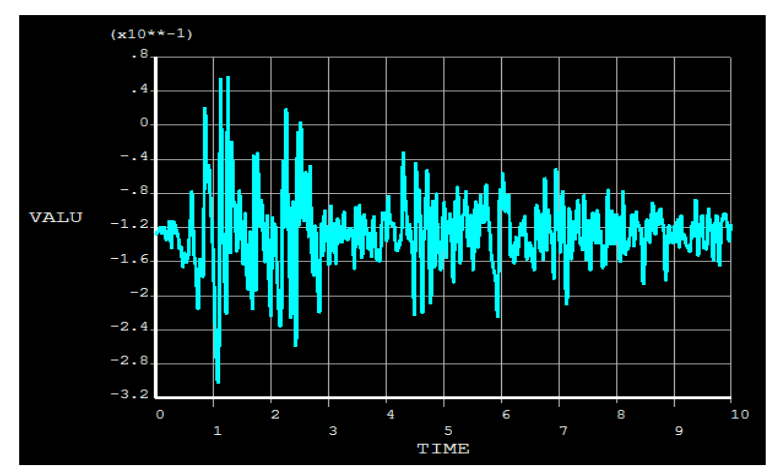

Fig. 25. Longitudinal Displacements of the top of tower under earthquake excitations
Transverse and longitudinal direction displacements are given in

Table 3 .

Table 3. Response of the Tower

\begin{tabular}{|l|l|l|l|}
\hline $\begin{array}{l}\text { Girder } \\
\text { location }\end{array}$ & $\begin{array}{l}\text { Vertical } \\
\text { Deformations } \\
(\mathrm{cm})\end{array}$ & $\begin{array}{l}\text { Transverse } \\
\text { Deformations } \\
(\mathrm{cm})\end{array}$ & $\begin{array}{l}\text { Longitudinal } \\
\text { Deformations } \\
(\mathrm{cm})\end{array}$ \\
\hline $\begin{array}{l}\text { At Tower } \\
\text { top }\end{array}$ & 7.0 & 33.4 & 30.7 \\
\hline $\begin{array}{l}\text { At Girder } \\
\text { level }\end{array}$ & 7.2 & 25.1 & 24.8 \\
\hline $\begin{array}{l}1 \mathrm{~m} \text { above } \\
\text { the bottom } \\
\text { of the } \\
\text { tower }\end{array}$ & 8.5 & 5.8 & 4.9 \\
\hline
\end{tabular}

Time history analysis of the CSB shows that the largest displacements or peak responses are not related to the peak ground accelerations, rather they are dependent on many other factors like bridge stiffness, nature of the earthquake ground excitations, modal shapes and mass distribution. However, the results show the general trend of cable stayed bridges.

\section{CONCLUSIONS}

Static and dynamic, modal and time history analyses of the three dimensional model were performed to study the dynamic response/behavior of cable stayed bridges. Some of the major findings from this study are summarized.

Cables can provide better restraints if they are modeled using a single element. Cables can sag, but they achieve better connectivity with the bridge girder and tower. The built-in force convergence of ANSYS can be replaced by displacement convergence technique to better control the iteration process. Deflection under the dead loads can be ignored because they are insignificant. To achieve more realistic results of the stiffness, pre-stressed modal analysis must be performed. CSB has low stiffness in the vertical direction. Time history analysis of the CSB shows that the largest displacements or peak responses are not related to the peak ground accelerations, rather they are dependent on many other factors like bridge stiffness, nature of the earthquake ground excitations, modal shapes and mass distribution. In the end, CSB exhibits elastic response, therefore, they can be constructed in the earthquake active areas with some special considerations.

\section{REFERENCES}


[3] S. ARZOUMANIDIS, A. SHAMA, and S. MARLOW, "SEISMIC PERFORMANCE OF THE NEW TACOMA NARROWS BRIDGE," 2004.

[4] J. F. Fleming and E. A. Egeseli, "Dynamic behaviour of a cable-stayed bridge," Earthquake Engineering \& Structural Dynamics, vol. 8, no. 1, pp. 1-16, 1980.

[5] A. S. Nazmy and A. M. Abdel-Ghaffar, "Threedimensional nonlinear static analysis of cable-stayed bridges," Computers \& structures, vol. 34, no. 2, pp. 257-271, 1990.

[6] A. M. Abdel-Ghaffar and A. S. Nazmy, "3-D nonlinear seismic behavior of cable-stayed bridges," Journal of Structural Engineering, vol. 117, no. 11, pp. 34563476, 1991.

[7] S. Parvez and M. Wieland, "Earthquake Behaviour of Proposed Multi-span Cable-stayed Bridge over River Jamuna in Bangladesh," in Proceedings of International Conference on Cable-stayed Bridges, Bangkok, Thailand, 1987, pp. 479-489.

[8] R. Karoumi, "Modeling of cable-stayed bridges for analysis of traffic induced vibrations," in Proc., IMAC-XVIII Conf. on Structural Dynamics, 2000, pp. 842-848.

[9] F. Au, Y. Cheng, Y. Cheung, and D. Zheng, "On the determination of natural frequencies and mode shapes of cable-stayed bridges," Applied Mathematical Modelling, vol. 25, no. 12, pp. 1099-1115, 2001.

[10] X. Shen, X. Wang, Q. Ye, and A. Ye, "Seismic performance of Transverse Steel Damper seismic system for long span bridges," Engineering Structures, vol. 141, pp. 14-28, 2017.

[11] S. Li, F. Zhang, J.-q. Wang, M. S. Alam, and J. Zhang, "Seismic responses of super-span cable-stayed bridges induced by ground motions in different sites relative to fault rupture considering soil-structure interaction," Soil Dynamics and Earthquake Engineering, vol. 101, pp. 295-310, 2017.

[12] X. Kang, L. Jiang, Y. Bai, and C. C. Caprani, "Seismic damage evaluation of high-speed railway bridge components under different intensities of earthquake excitations," Engineering Structures, vol. 152, pp. 116-128, 2017.

[13] B. Atmaca, M. Yurdakul, and Ş. Ateş, "Nonlinear dynamic analysis of base isolated cable-stayed bridge under earthquake excitations," Soil Dynamics and Earthquake Engineering, vol. 66, pp. 314-318, 2014.

[14] A. M. Abdel-Ghaffar and H. Ali, "Toward seismic isolation of cable-stayed bridges," in Proceedings of the Sixth US-Japan Workshop on Bridge Engineering, 1990, pp. 515-529.

[15] J. C. Wilson and W. Gravelle, "Modelling of a cablestayed bridge for dynamic analysis," Earthquake Engineering \& Structural Dynamics, vol. 20, no. 8, pp. 707-721, 1991.

[16] W.-X. Ren and M. Obata, "Elastic-plastic seismic behavior of long span cable-stayed bridges," Journal of Bridge Engineering, vol. 4, no. 3, pp. 194-203, 1999.

[17] L. Zhu, H. Xiang, and Y. Xu, "Triple-girder model for modal analysis of cable-stayed bridges with warping effect," Engineering structures, vol. 22, no. 10, pp. 1313-1323, 2000.

[18] X. Chen and Y. Liu, Finite element modeling and simulation with ANSYS Workbench. CRC Press, 2014.

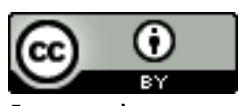

Journal of Applied and Emerging Sciences by BUITEMS is licensed under a Creative Commons Attribution 4.0 International License. 